DOI:

\title{
Dolgu Duvarlı Betonarme Binaların Hakim Periyodunun Doğrudan Formüller ile Elde Edilmesi
}

\author{
Muzaffer BÖREKÇ $\dot{I}^{1 *}$ \\ ${ }^{1}$ Yıldız Teknik Üniversitesi, İnşaat Mühendisliği Bölümü, İstanbul, Türkiye \\ ORCID ID: orcid.org/0000-0002-8684-6159
}

Geliş Tarihi: 20.08 .2019

*Sorumlu Yazar e mail: mborekci@inm.yildiz.edu.tr Kabul Tarihi: 24.09.2019

Atıf/Citation: Börekçi, M. "Dolgu Duvarlı Betonarme Binaların Hakim Periyodunun Doğrudan Formüller ile Elde Edilmesi”, Haliç Üniversitesi Fen Bilimleri Dergisi 2019, 2/2: 161-178.

Araştırma Makalesi/ Research Article

\section{Özet}

Bina tasarımında doğal periyotların elde edilmesi önemli bir husustur. Kat adedi az, düzensizliklerin olmadığı binalarda hakim mod öteleme modudur ve bu tip binaların tek serbestlik dereceli gibi düşünülmesi mümkündür. Öteleme modu hakim ve eşdeğer tek serbestlik dereceli olarak kabul edilebilecek binaların deprem yükleri altındaki tasarımında tek mod kullanılabileceğinden, yalnızca bu modun periyodunu elde etmek yeterli olacaktır. Uzun hesaplara gerek olmadan hızlı bir şekilde bu periyodu elde etmeye yarayacak doğrudan formüller literatürde çeşitli çalışmalarda önerilmiştir. Binalarda odalar oluşturabilmek amacıyla duvarlar örülmektedir ve bu duvarların rijitliğe olan katkısı ile periyodu değiştireceği açıktır. Fakat tasarım sırasında duvarların rijitliğe katkısı ihmal edilmekte yalnızca ağırlığı dikkate alınmaktadır. Literatürde periyot elde edebilmek için önerilen doğrudan formüllerin bazıları duvarın etkisini dikkate almazken bazıları duvar rijitliğinin katkısını hesaba katmaktadır. Bu çalışmada, Türkiye'deki bina stoğunu temsil edebileceği düşünülen 6 katlı betonarme çerçevelerden oluşan bir binanın hakim periyodu hem SAP2000 programında modellenerek analitik olarak hem de doğrudan formüller ile elde edilmiştir. Duvarlı ve duvarsız olmak üzere iki ayrı model ile bina periyotlarının elde edildiği bu çalışmada, önerilen formüllerin periyodu elde etmedeki yaklaşıklıkları ve duvar etkisini ne kadar dikkate aldıkları araştırılmıştır.

Anahtar Kelimeler: Betonarme, Dolgu duvar, Periyot, Modal analiz, Rijitlik. 


\title{
Estimation of the Fundamental Period of Reinforced Concrete Buildings with Infill Wall using Direct Formulas
}

\begin{abstract}
Estimation of natural periods is of great importance in building design. Translational mode is the dominant mode in case of buildings with few storeys and no irregularities, and such buildings can be considered as single degree of freedom systems. Since only one mode can be used in the design of buildings, which have the dominant mode as translation mode and can be considered as an equivalent single degree of freedom system, under earthquake loads, it is sufficient to determine only the period of this mode. There exist equations for estimating this period directly without the need for long calculations in the literature. It is obvious that infill walls used for forming rooms in a structure will change the period of the structure since they contribute to the stiffness of the structure. However, in the design procedure, the contribution of the walls to the stiffness is neglected and only the weight is taken into consideration. In the literature, some of the equations proposed for estimating the period do not take into account the effect of infill walls, while others do. In this study, the fundamental period of a 6-storey reinforced concrete frame building, which can be assumed to represent the building stock in Turkey, has been estimated both with analytical methods using SAP2000 and equations available in the literature. The accuracy of the proposed equations for estimating the period of the hypothetical building with and without infill walls and considering the effect of infill walls on the period have been investigated.
\end{abstract}

Keywords: Reinforced concrete, Infill Wall, Period, Model analysis, Rigidity

\section{Giriş}

Depremselliği yoğun bir bölgede bulunan ülkemizdeki mevcut yapıların deprem riskinin belirlenmesi ve yeni yapılacak yapıların depreme dayanıklı olarak tasarlanması çok önemli bir husustur. Depreme dayanıklı yapı tasarımında veya mevcut yapıların deprem güvenilirliğinin belirlenmesinde, "kuvvet esaslı" ve "yerdeğiştirme esaslı" olmak üzere iki temel yöntem kullanılmaktadır. Yerdeğiştirme esaslı yöntem, göreli olarak yeni ve daha karmaşık bir yöntem olmasına rağmen daha 
gerçekçi bir yaklaşımdır. Büyük depremlerde oluşan hasarların, yapılarda meydana gelen büyük yerdeğiștirmelerden kaynaklandığı bilinmektedir. Mühendisler tarafindan çok daha fazla tercih edilen ve tasarımda kullanılan diğer yöntem olan kuvvet esaslı yöntem, yapıdaki sabit ve hareketli yükler ile birlikte depremden dolayı oluşacak kuvvetlere göre taşıyıcı sistemin tasarlanması esasına dayanmaktadır. Tasarımda her iki yöntemden herhangi biri kullanılsa da tasarımı yapılacak yapının doğal periyodunun çok doğru bir şekilde tahmin edilmesi en önemli hususlardan biridir. Yüksekliği fazla olmayan ve düzensizlikleri az olan binalarda hakim mod öteleme modudur ve bu tip binalar tek serbestlik dereceli gibi kabul edilebilirler. Böylelikle, yalnızca öteleme moduna ait periyodun elde edilmesi, tasarımda yeterli bir parametre olacaktır. Bilindiği üzere binalarda kullanım alanlarını ayırmak için duvarlar örülmekte ve tasarımda duvarların yapısal olmayan eleman olarak kabul edilmesinden dolayı binanın davranışına etkisi ihmal edilmektedir [1], [2]. Duvarların tasarımdaki tek rolü bina ağırlığında dikkate alınmasıdır. Fakat duvarların betonarme binaların davranışını önemli ölçüde etkilediği yapılan bazı çalışmalarda gösterilmiştir [3], [4], [5], [6]. Duvarları yapısal olmayan eleman olarak kabul ederek tasarımda dikkate almamak, bina periyodunun hesabında güvenilir olmayan sonuçlar elde etmemize sebep olmaktadır [7]. Duvarlar taşıyıcı eleman olarak kabul edildiğinde binanın rijitliğini artırarak periyodu kısaltacağı açıktır. Türkiye Bina Deprem Yönetmeliği (TBDY) 2018'de [8] verilen tasarım spektrumunun şekli düşünüldüğünde, standart binalarda periyot kısaldıkça binaya gelecek deprem kuvveti artacaktır. Dolayısıyla, bina periyodunun en doğru şekilde elde edilmesi daha doğru tasarımlar yapmamızı sağlayacaktır. Öteleme modu hakim olan binaların periyodunun elde edilmesinde doğrudan analitik çözüm programlarından yararlanılabileceği gibi, basitleştirilmiş formüllerle de elde etmemizi sağlayan çalışmalar mevcuttur. Hakim periyodu doğrudan elde etmekte kullanılan bu bağıntılar genellikle bina yüksekliği, kat adedi, bina oturumunun uzunluğunu dikkate alırken, çok azı dolgu duvarları dikkate almaktadır. Bu çalışmada, 6 katlı ve 
Türkiye'deki genel bina stoğunu temsil ettiği düşünülen betonarme bir binanın hakim periyodu analitik model ve literatürde önerilen doğrudan formüllerle elde edilerek bu formüllerin güvenilirlikleri araşt1rılmıştır. Analitik model SAP2000 [9] programında duvarlı ve duvarsız olarak hazırlanmış ve özdeğer analizi ile periyot elde edilmiştir. Literatürde önerilen formüllerle elde edilen periyotların SAP2000 [9] modelleri ile uygunluğu araştırılmıştır. Aynı zamanda duvarların davranışa etkisi araştırılmış ve önerilen bağıntıların duvarlı ve duvarsız durumdaki periyotlara yakınlığı incelenmiştir. Bu sayede hangi bağıntının duvarın rijitliğe katkısını dikkate aldığı da belirlenmiştir.

\section{Materyal ve Metot}

Bu çalışmada, Türkiye'de bulunan ev tipi bina stoğunu temsil ettiği düşünülen 6 katlı betonarme bir bina SAP2000 [9] programında duvarlı ve duvarsız olarak modellenerek bina periyodu elde edilmiştir. Aynı zamanda literatürde önerilen formüller ile bina periyodu doğrudan elde edilerek, analitik sonuçlar karşılaştırılmıştır. Böylece, hem duvarların periyoda etkisi hem de mevcut formüller ile elde edilen sonuçların güvenilirliği araştırılmıştır.

\section{1. İncelenen bina ve özellikleri}

İncelenen bina hipotetik bir bina olup her iki yönde 3 açıklığa sahiptir ve açıklıkları 6 m'dir. 6 katlı binanın kat yükseklikleri sabit 3 m'dir ve toplam kat yüksekliği 18 m'dir. Binada kullanılan beton C30 ‘dur. Bina rijitliğini, dolayısıyla periyodu etkileyen beton elastisite modülü (E c) TS500-2000'de [10] verilen denklem ile belirlenmiştir. Beton elastisite modülü aşağıda verilen Denklem (1) ile elde edilmiştir. C30 betonu için beton elastisite modülü $31800 \mathrm{MPa}$ 'dır.

$$
E_{c}=14000+3250 \sqrt{f_{c k}}
$$


Şekil 1'de kalıp planı görülen binanın Kiriş boyutları 25/50 (cm/ cm)'dir ve kolon boyutları Tablo 1'de verilmiştir.

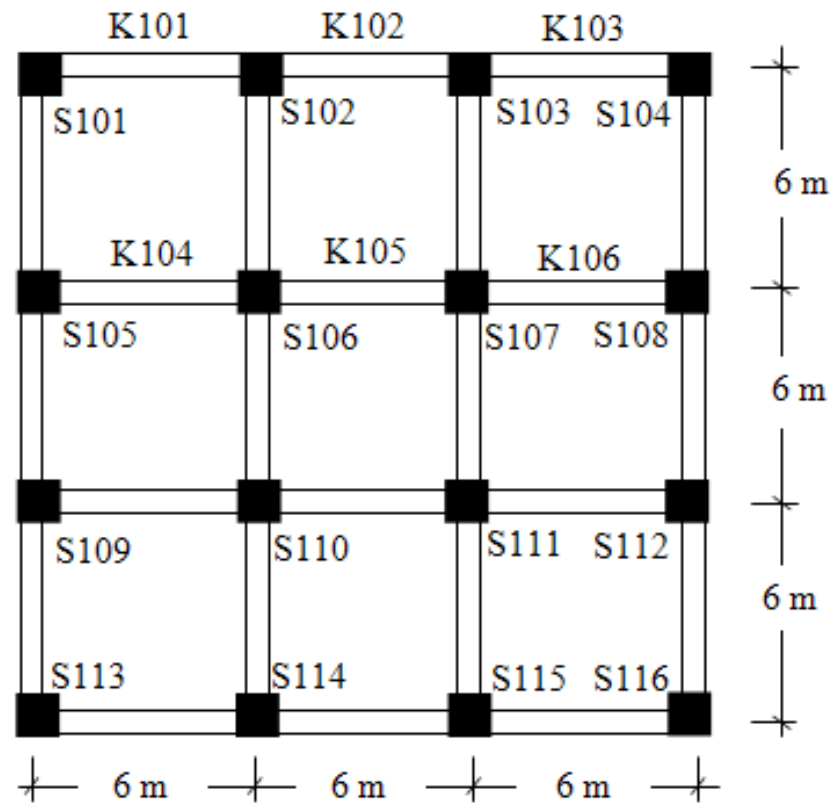

Şekil 1. Bina kalıp planı

Tablo 1. Kolon boyutları

\begin{tabular}{cc}
\hline Kolon No & Kesit Boyutlar1 $(\mathrm{cm} / \mathrm{cm})$ \\
\hline S101 & $35 / 35$ \\
S102 & $40 / 40$ \\
S105 & $40 / 40$ \\
S106 & $50 / 50$ \\
\hline
\end{tabular}

\subsection{Dolgu duvarların analitik modelleri}

Dolgu duvarların binanın davranışına etkisinin olduğu iyi bilinmektedir. $\mathrm{Bu}$ sebeple, literatürde önerilen periyot formüllerinin 
güvenilirliğinin araştırılmasında dolgu duvarın etkisi de incelenmiştir. Taşıyıcı sistem elemanı olarak dolgu duvarları dikkate alan birçok çalışma yapılmıştır. Bu konudaki ilk çalışma Polyakov [11] tarafından 1956 yılında yapılmıştır. Ardından Holmes [12], dolgu duvarın yerine duvarla aynı kalınlıkta ve malzemede iki ucu mafsallı eşdeğer diyagonal çubuk kullanmıştır ve bu eşdeğer çubuğun genişliği, diyagonal çubuğun uzunluğunun 1/3 katıdır. Smith [13], Smith ve Carter [14], Holmes'un [12] önerisine benzer bir modelleme tekniği ile iki ucu mafsallı olan iki adet eşdeğer diyagonal çubuk kullanmayı önermişleridir. Bu çubukların kesit genişlikleri çubuk/çerçeve etkileşim yüzeylerinin genişlikleri olarak kabul edilmiştir. Mainstone [15] dolgulu çerçevenin rijitlik ve dayanımını kullanarak eşdeğer çubuk genişliği hesaplamıştır. Bu yaklaşım FEMA 306 [16] ve TBDY 2018 [8] tarafindan da benimsenmiştir. Bu çalışmada duvar modellemesinde Mainstone [15], FEMA306 [16] ve TBDY 2018'de [8] önerilen eşdeğer çubuk yöntemi kullanılmıştır. Şekil 2'de, eşdeğer basınç çubuğu ve genişliği gösterilmiştir.

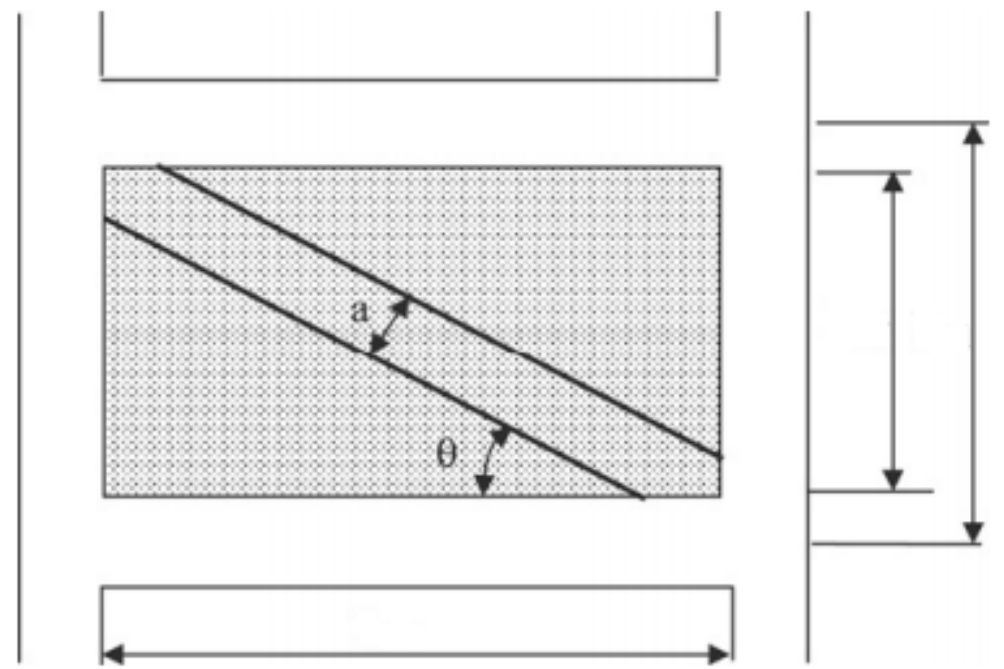

Şekil 2. Eşdeğer basınç çubuğu 
Denklem (2) - (4) arasında eşdeğer basınç çubuğunun modellenmesi için gerekli parametrelerin elde edilmesi verilmiştir.

$$
a=0.175\left(\lambda_{d} h_{k}\right)^{-0.4} r_{d}
$$

Denklem (2)'de a basınç çubuğunun genişliği, $h_{k}$ kolon boyu, $r_{d}$ dolgu duvarı köşegen uzunluğudur. $\lambda_{d}$ Denklem (3) ile elde edilmektedir.

$$
\begin{aligned}
& \lambda_{d}=\left[\frac{E_{d} t_{d} \sin 2 \theta}{4 E_{c} I_{k} h_{d}}\right]^{1 / 4} \\
& \theta=\tan ^{-1}\left(\frac{h_{d}}{L_{d}}\right)
\end{aligned}
$$

$E_{d}$ ve $E_{c}$ dolgu duvarı ve çerçeve betonun elastisite modülü, $t_{d} d u-$ var kalınlığ $1, h_{d}$ duvar yüksekliği, $I_{k}$ kolonun atalet momenti ve $\theta$ köşegenin yatay ile olan açısıdır.

Bu çalışmada C30 betonu için $\mathrm{E}_{\mathrm{c}}=31800 \mathrm{MPa}$, sıvalı tuğla duvar için ise $\mathrm{E}_{\mathrm{d}}=4200 \mathrm{MPa}$ elastisite modülleri kullanılmıştır. Duvar kalınlığ $\mathrm{t}_{\mathrm{d}}=13.5 \mathrm{~cm}$ 'dir.

Bilindiği gibi dolgu duvarlar bazı alanlarda tamamen dolu iken bazı alanlarda kapı ve pencere boşlukları bulunmaktadır. Ersin vd. [17] boşluk etkisini dikkate almak üzere eşdeğer basınç çubuğunun uzama rijitliği EA'yı bir $\beta$ katsayısı ile çarpmışlardır. Şekil 3’te bir örneği gösterilen kapı, pencere gibi farklı boşluk tipleri ve boyutları için $\beta$ katsayısı önermişlerdir. Bu çalışmada, kapı boşlukları ihmal edilerek iç duvarlar tam dolu kabul edilmiş, diş çerçevede bulunan duvarlarda ise pencere boşlukları olduğu varsayılmıştır. Ersin vd. [17], 140/120 $\mathrm{cm} / \mathrm{cm}$ pencere boşluğu için $\beta=0.2$ katsayısının kullanılmasının yeterli olacağını belirtmişlerdir. Böylece, dış duvarlarda bulunan pencere boşluklarının rijitliğe olan etkisi dikkate alınmıştır. 


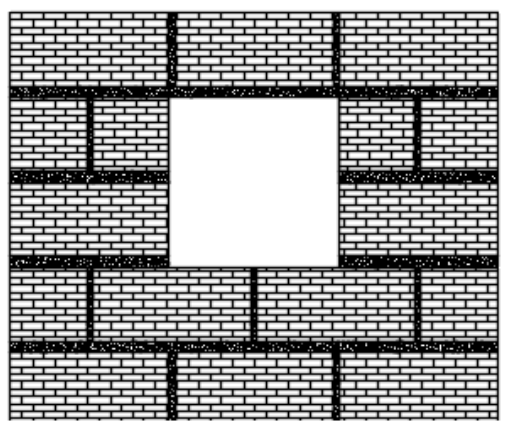

Şekil 3. Dolgu duvarda bulunan bir pencere boşluğu

\subsection{Bina analitik modeli}

Bina analitik modeli SAP2000 [9] bilgisayar programında hazırlanmıştır. Sıva ve kaplama yükü $1.2 \mathrm{kN} / \mathrm{m}^{2}$, hareketli yük ise $2 \mathrm{kN} / \mathrm{m}^{2}$ ' dir. Duvarlar iki ucu mafsallı eşdeğer diyagonal çubuklarla modellenmiştir. Şekil 4'te duvarsız ve duvarlı olarak modellenen binanın SAP2000 [9] görüntüsü verilmiştir.
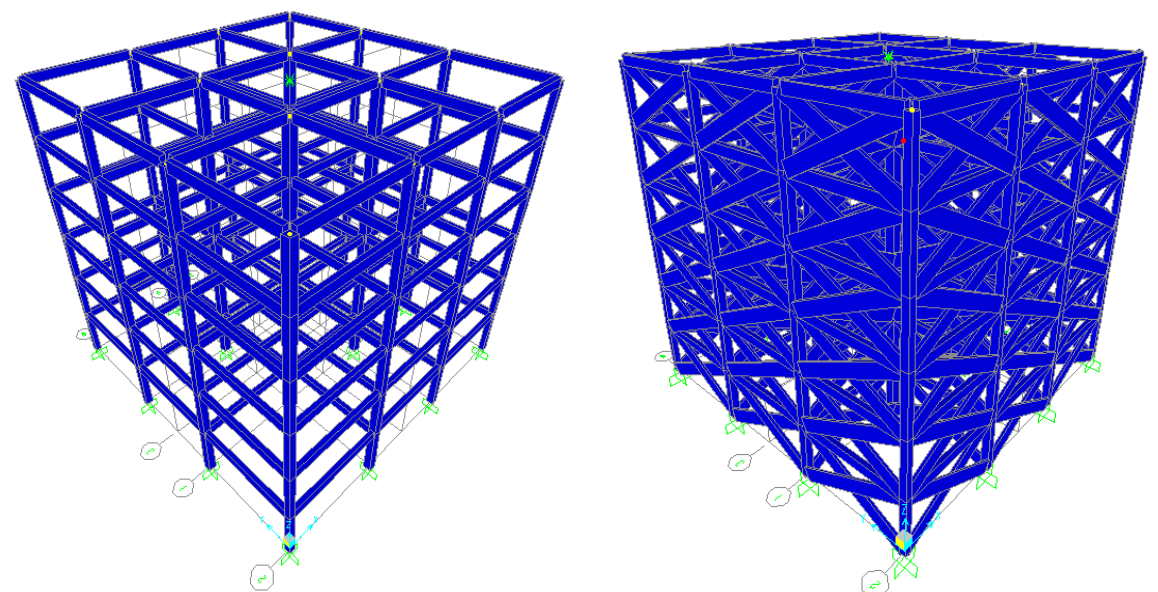

Şekil 4. Binanın SAP2000 [9] modeli 


\subsection{Literatürde önerilen periyot formülleri}

Literatürde ve yönetmeliklerde, hakim mod periyodunun doğrudan elde edilmesini sağlayan formüller önerilmiştir. $\mathrm{Bu}$ formüller sayesinde tasarımda ihtiyaç duyulan hakim mod periyodu hızlıca elde edilerek tasarıma başlanabilmekte veya ön tasarım için gerekli yaklaşık tesirler veya boyutlar belirlenebilmektedir. Türk Deprem Yönetmeliği (TDY) 1998 [18], TBDY 2018 [8] ve UBC 1997 [19] aşağıda verilen Denklem (5)'i önermiştir. Denklem (5)'te önerilen formülde duvarların rijitliğe katkısı dikkate alınmamıştır.

$$
\mathrm{T}_{\mathrm{d}}=\mathrm{C}_{\mathrm{t}} \cdot \mathrm{H}^{3 / 4}
$$

Denklem (5)'te H toplam bina yüksekliği, $\mathrm{C}_{\mathrm{t}}$ ise bina tipi ve malzemesine göre değişen bir katsayıdır. Taşıyıcı sistemi yalnızca betonarme çerçevelerden oluşan binalar için TDY 1998 [18] $\mathrm{C}_{\mathrm{t}}=0.07$, TBDY 2018 [8] $\mathrm{C}_{\mathrm{t}}=0.1$ ve $\mathrm{UBC}$ ise $\mathrm{C}_{\mathrm{t}}=0.0731$ değerlerini önermişlerdir.

Goel ve Chopra [20] hakim mod periyodu için Denklem (6) ve Denklem (7)'de alt ve üst limitleri içeren bir formül önermişlerdir. Alt limit olan $\mathrm{T}_{\mathrm{Ld}}$ yerdeğiştirme esaslı tasarımda kullanmak için, üst limit olan $\mathrm{T}_{U d}$ kuvvet esaslı tasarımda kullanmak için daha uygundur. Önerilen bu bağıntılarda duvar etkisi doğrudan dikkate alınmamıştır.

$$
\begin{aligned}
& \mathrm{T}_{\mathrm{Ld}}=0.047 \mathrm{H}^{0.9} \\
& \mathrm{~T}_{\mathrm{Ud}}=0.067 \mathrm{H}^{0.9}
\end{aligned}
$$

Güler vd. [21] Denklem (8)'de verilen formülü önermişlerdir. Denklem (8)'de önerilen formülde dolgu duvarın rijitliğe katkısı dolaylı olarak dikkate alınmıştır. Yaptıkları çalışmada tuğla malzemenin elastisite modülü $\mathrm{E}_{\mathrm{d}}=6000 \mathrm{MPa}$ ve tuğla kalınlığı ise $\mathrm{t}=150 \mathrm{~mm}$ olarak kabul edilmiştir. 


$$
\mathrm{T}_{\mathrm{d}}=0.026 \mathrm{H}^{0.9}
$$

Koçak ve Yıldırım [22] ise dolgu duvarın rijitliğe etkisini dikkate alan Denklem (9)'daki formülü önermişlerdir.

$$
\begin{aligned}
& \mathrm{T}_{\mathrm{d}}=\mathrm{T}_{\mathrm{c}}(1-\Delta \mathrm{T} / 100) \\
& \Delta \mathrm{T}(\%)=69.1 \mathrm{~A}_{\mathrm{k}}^{1.08}
\end{aligned}
$$

Denklem (10)'da $A_{k}$ dolgu duvar alanının kolon alanı ve duvar alanlarının toplamına oranıdır. $T_{c}$ duvarsız çıplak çerçeveli binanın periyodudur. Denklem (9)'da önerilen formül elastisite modülü $\mathrm{E}_{\mathrm{d}}=6000$ $\mathrm{MPa}$ ve kalınlığ 1 ise $\mathrm{t}=150 \mathrm{~mm}$ olan tuğlalı duvarlar için önerilmiştir. $\mathrm{Bu}$ formül ile hakim periyotta duvarın katkısını dikkate almak amaçlanmıştır.

Koçak vd. [23] dolgu duvarın rijitliğe katkısını da dikkate alan bir formül önermişlerdir. Denklem (11)'de verilen eşitlikte daha önce açıklanan eşitliklerden farklı olarak tuğlanın elastisite modülü ve kalınlığ da parametre olarak yer almaktadır. Pratikte görülebilecek farklı elastisite modülleri ve tuğla kalınlıklarının kombinasyonları için çözümler yapılarak önerilen formül, olası elastisite modülü ve kalınlık çiftleri için sonuçlar vermektedir.

$$
T_{d}=\frac{x_{1} H^{x_{2}}}{E^{x_{8}} t^{x_{4}}}
$$

Denklem (11)'de H toplam bina yüksekliğini, E tuğlanın elastisite modülünü $(\mathrm{MPa}), \mathrm{t}$ duvar kalınlığını $(\mathrm{mm})$ ifade etmektedir. $\mathrm{x}_{1}, \mathrm{x}_{2}, \mathrm{x}_{3}$ ve $\mathrm{x}_{4}$ ise katsayılardır. Bu katsayılar Tablo 2'de verilmiştir. 
Tablo 2. Denklem (11)'de verilen katsayılar

\begin{tabular}{cl}
\hline Katsayılar & Değerleri \\
\hline $\mathrm{x}_{1}$ & 2.005195 \\
$\mathrm{x}_{2}$ & 0.858439 \\
$\mathrm{x}_{3}$ & 0.301073 \\
$\mathrm{x}_{4}$ & 0.297021 \\
\hline
\end{tabular}

\section{Bulgular}

Yüksekliği az, düzensizliği bulunmayan binalarda bir doğrultudaki öteleme modu hakim olduğunda, bu bina eşdeğer tek serbestlik dereceli gibi düşünülebilmektedir. TBDY 2018'de [8], bir doğrultudaki öteleme modunun katılımı \%70 ise bu binanın eşdeğer tek serbestlik dereceli olarak kabul edilebileceği belirtilmektedir.

\subsection{Modal analiz sonuçları}

SAP2000 [9] programında modellenen bina her iki yönde de simetrik olduğundan, X ve Y doğrultularındaki mod katılımları ve periyotları aynıdır. Dolayısıyla verilen değerler her iki doğrultu için de geçerlidir. Tablo 3 'te periyot ve mod katılımı verilmiştir. Şekil 5'te duvarsız modelin öteleme modunun şekli hem plan olarak hem de 3 boyutlu olarak verilmiştir. Şekil 6'da ise duvarlı modelin öteleme modunun şekli hem plan olarak hem de 3 boyutlu olarak verilmiştir. Tablo 3 'te periyot ve mod katılımı verilmiştir.

Tablo 3. Binanın hakim mod periyotları ve katılım oranları

\begin{tabular}{ccc}
\hline Bina & Periyot $(\mathrm{sn})$ & X doğrultusu katılımı (\%) \\
\hline Duvarsı Model & 0.684 & 84.2 \\
Duvarlı Model & 0.396 & 84.4 \\
\hline
\end{tabular}




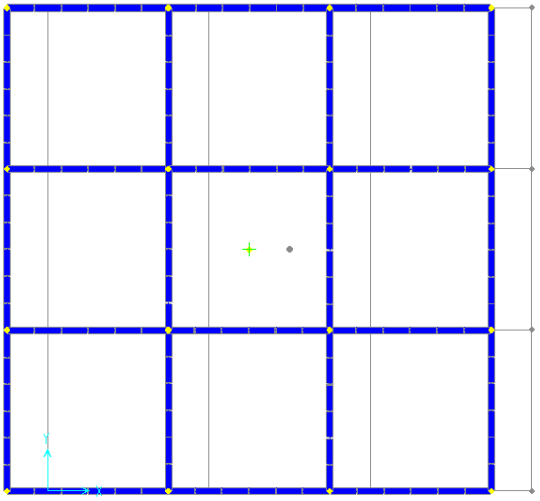

a) Planda öteleme modu

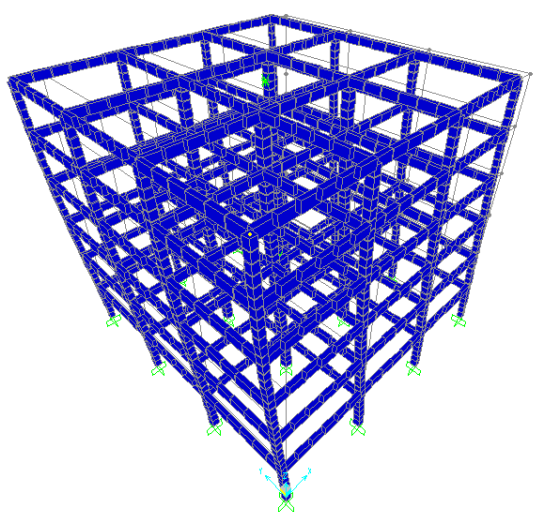

b) 3D öteleme modu

Şekil 5. Bina duvarsız modelinin X doğrultusu öteleme modu

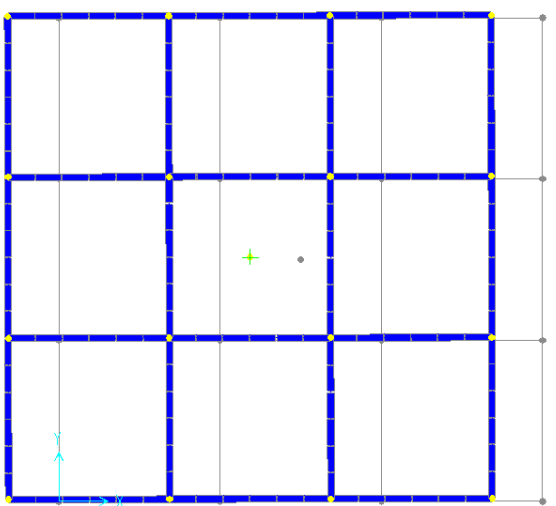

a) Planda öteleme modu

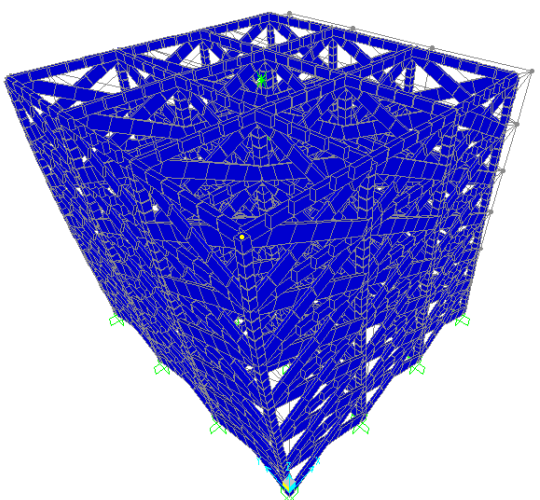

b) 3D öteleme modu

Şekil 6. Bina duvarlı modelinin X doğrultusu öteleme modu

\subsection{Doğrudan bağıntılar ile elde edilen periyotlar}

Bu çalışmada dikkate alınan binanın toplam yüksekliği $\mathrm{H}=18$ m'dir. Dolgu duvar için kullanılan tuğlanın kalınlığ $\mathrm{t}=135 \mathrm{~mm}$ ve elastisite modülü ise $\mathrm{E}_{\mathrm{d}}=4200 \mathrm{MPa}$ 'dır. Koçak ve Yıldırım'ın [22] önerdiği bağıntıda kullanılmak üzere; 
Bir kattaki kolon alanı $=2.77 \mathrm{~m}^{2}$

Bir kattaki duvar alanı $=18.063 \mathrm{~m}^{2}$

$\mathrm{A}_{\mathrm{k}}=18.063 /(18.063+2.77)=0.867$

Tablo 4'te bina analitik modelinden ve doğrudan formüller ile elde edilen periyotlar, Şekil 7'de ise bu periyotların grafik olarak gösterimi verilmiştir.

Tablo 4. Binanın hakim mod periyodunun farklı bağıntılar ile elde edilen değerleri

\begin{tabular}{cc}
\hline Yöntem & Periyot (sn) \\
\hline Duvarsız Analitik Model & 0.684 \\
Duvarlı Analitik Model & 0.396 \\
TDY 1998 & 0.612 \\
TBDY2018 & 0.873 \\
UBC 1997 & 0.639 \\
Goel ve Chopra $\left(\mathrm{T}_{\mathrm{L}}\right)$ & 0.634 \\
Goel ve Chopra $\left(\mathrm{T}_{\mathrm{U}}\right)$ & 0.903 \\
Güler vd. & 0.350 \\
Koçak ve Yıldırım & 0.278 \\
Koçak vd. & 0.453 \\
\hline
\end{tabular}

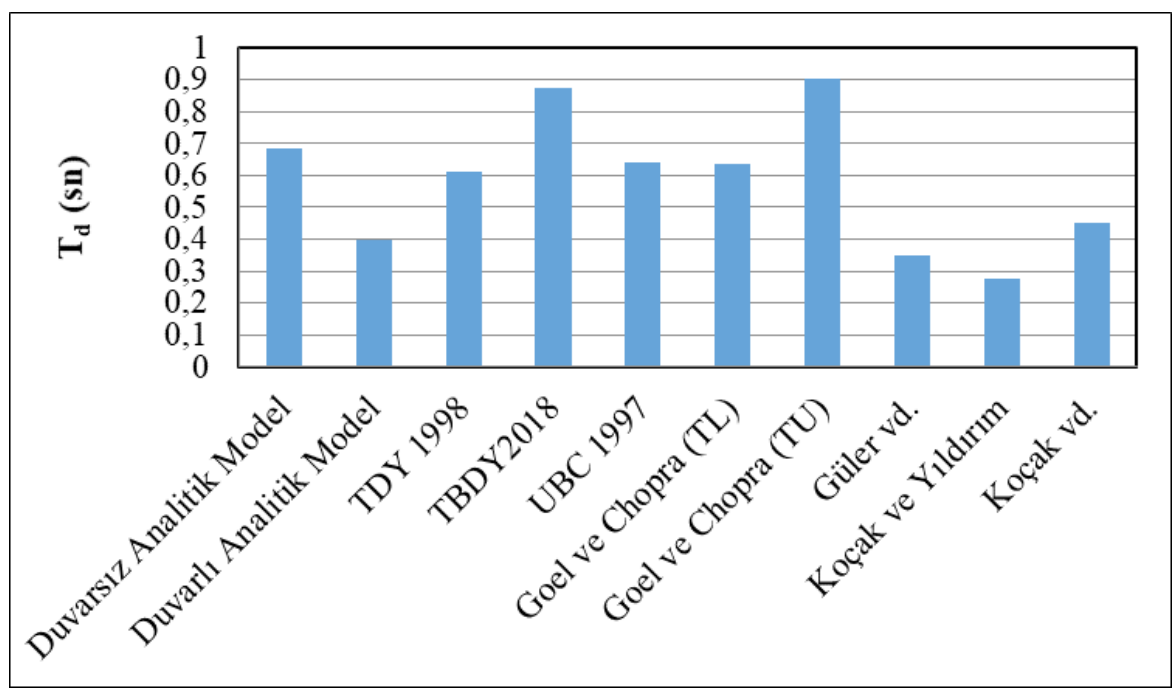

Şekil 7. Binanın farkı bağıntılar ile elde edilen periyotları 


\section{Tartışma}

Binanın SAP2000 [9] modeli ve literatürde önerilen bağıntılar ile elde edilen bağıntılar karşılaştırılmış ve hangi bağıntının analitik sonuçlara daha yakın sonuçlar verdiği araştırılmıştır. Tablo 5'te duvarlı ve duvarsız bina modelinin periyodunun önerilen bağıntılarla elde edilen periyotlara oranı verilmiştir. Şekil 8'de duvarsız bina modelinin periyodunun, Şekil 9'da ise duvarlı bina modelinin periyodunun önerilen bağıntılarla elde edilen periyotlara oranı grafik olarak verilmiştir.

Tablo 5. Duvarlı ve duvarsiz model ile elde edilen periyodun önerilen bağıntılarla elde edilen periyotlara oranı

\begin{tabular}{ccc}
\hline Yöntem & Duvarsız Model / Bağıntı & Duvarlı Model / Bağıntı \\
\hline TDY 1998 & 1.12 & 0.65 \\
TBDY2018 & 0.78 & 0.45 \\
UBC 1997 & 1.07 & 0.62 \\
Goel ve Chopra $\left(\mathrm{T}_{\mathrm{L}}\right)$ & 1.08 & 0.62 \\
Goel ve Chopra $\left(\mathrm{T}_{\mathrm{U}}\right)$ & 0.76 & 0.44 \\
Güler vd. & 1.95 & 1.13 \\
Koçak ve Y1lırım & 2.46 & 1.42 \\
Koçak vd. & 1.51 & 0.87 \\
\hline
\end{tabular}

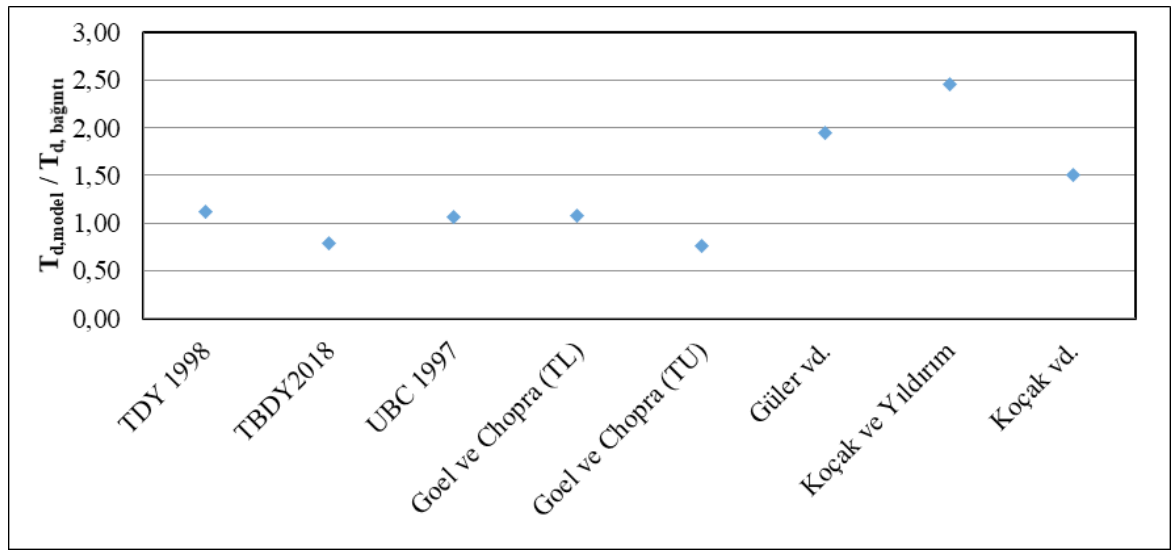

Şekil 8. Duvarsız model periyodunun bağıntılarla elde edilen periyoda oranı 


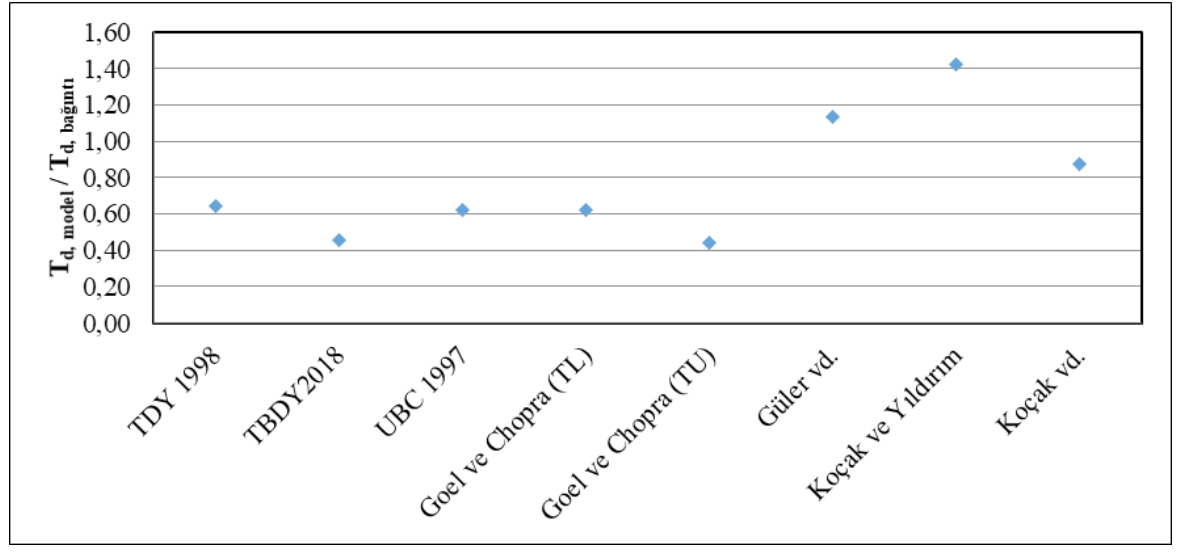

Şekil 9. Duvarlı model periyodunun bağıntılarla elde edilen periyoda oranı

Tablo 5'ten ve Şekil 8'den görüldüğü üzere duvarsız modele en yakın sonuçları TDY 1998 [18], TBDY 2018 [8], UBC 1997 [19], Goel ve Chopra'nın [20] alt limit bağıntı önerileri vermiştir. Goel ve Chopra'nın [20] önerdiği üst limit değer bağıntısı daha uzak sonuçlar vermiştir. Oranlara bakıldığından UBC 1997 [19] ve Goel - Chopra [20] alt limit bağıntıları neredeyse analitik modelle aynı sonuçları vermektedir. Güler vd. [21], Koçak ve Yıldırım [22], Koçak vd. [23] tarafindan önerilen bağıntılar ise duvarın rijitliğe katkısını dikkate aldığından duvarsiz modelin analitik olarak elde edilen periyodundan daha kisa periyotlar vermektedirler.

Tablo 5'ten ve Şekil 9'dan duvarı model periyodu ile bağıntılarla elde edilen periyotların oranları verilmiştir. Sonuçlara göre duvarlı modelin periyoduna en yakın sonuçları yalnızca Güler vd. [21] ve Koçak vd. [23] tarafından önerilen bağıntılar vermişlerdir. Güler vd. [21] bağıntısı daha kısa periyot elde ederken Koçak vd. [23] bağıntısı daha uzun periyot elde etmiştir fakat iki bağıntının da analitik periyoda farkları neredeyse eşittir. Duvar etkisini dikkate almayan diğer bağıntılar oldukça uzak sonuçlar vermişlerdir. Duvarları dikkate alarak önerilen bağıntılar sabit bir tuğla kalınlığı ve elastisite modülü dikkate alınmıştır. Halbuki Koçak vd. [23] tarafından önerilen bağıntı 
olası tuğla kalınlıkları ve elastisite modüllerinin kombinasyonları ile elde edilmiştir. $\mathrm{Bu}$ açıdan birçok dolgu duvar rijitliğini temsil edebilmektedir.

\section{Sonuçlar}

$\mathrm{Bu}$ çalışmada betonarme çerçevelerden oluşan bir binanın hakim öteleme modu periyoduna duvarların taşıyıcı sistem elemanı olarak kabul edilmesinin etkisi ve bu periyodun elde edilebilmesi amaciyla literatürde önerilen bazı bağıntıların etkinlikleri araştırılmıştır. Bu amaçla, Türkiye' deki yapı stoğunu temsil edebileceği düşünülen 6 katlı betonarme çerçeveli bir bina modeli hem duvarsız hem de duvarlı olarak SAP2000 [9] programı ile modellenmiş ve analitik olarak periyotlar elde edilmiştir. Yapılan analizler ve hesaplar sonucu elde edilen sonuçlar aşağıda verilmiştir.

- Duvarsiz modelin periyodu $\mathrm{T}_{\mathrm{d}}=0.684 \mathrm{sn}$ iken duvarlı modelin periyodu $\mathrm{T}_{\mathrm{d}}=0.396$ sn'dir. Duvarlar taşıyıcı sistem elemanı olarak dikkate alındığında periyot neredeyse yarı yarıya kısalmaktadır. TBDY 2018'de [8] verilen tasarım spektrumu düşünüldügünde, kisalan bu periyot ile elde edilecek deprem kuvveti daha fazla olacaktır. Bu nedenle duvarı taşıyıcı sistem elemanı olarak dikkate almamak deprem açısından güvensiz sonuçlar verecektir.

- Duvarsız model periyodunun önerilen bağıntılarla elde edilen periyotlara oranı incelendiğinde TDY 1998 [18], TBDY 2018 [8], UBC 1997 [19], Goel ve Chopra [20] alt limit bağıntıları en yakın sonuçları vermektedir. TDY 1998 [18] bağıntısı ile \%12 oranda daha kısa periyot elde edilirken TBDY 2018 bağıntısı ile $\% 22$ oranda daha uzun periyot elde edilmektedir. Uzun periyot elde etmek deprem hesabı sırasında güvensiz sonuçlar elde etmemizi sağlayacaktır. UBC 1997 [19] ile Goel ve Chopra [20] bağıntıları nerdeyse analitik sonuca benzer sonuçlar vermiştir. 
Duvarın rijitliğe katkısı dikkate alınmadığı durumlarda UBC 1997 [19] ile Goel ve Chopra [20] bağıntıları güvenilir sonuçlar vermektedir.

- Duvarlı model periyodunun önerilen bağıntılarla elde edilen periyotlara oranı incelendiğinde en yakın değerleri Güler vd. ve Börekçi vd. bağıntıları vermektedir. Her iki bağıntı da \%13 oranında farklı sonuç bulsa da elde edilen değerler yeterli yaklaşıklıktadır. Güler vd. [21] bağıntısı daha kısa periyot bulurken Koçak vd. [23] bağıntısı ise Güler vd. [21] ile aynı oranda fakat daha uzun periyot bulmaktadır. Deprem hesabı açısından Güler vd. bağıntısı daha güvenli tarafta kalmaktadır.

- Yapılan çalışmalar, dolgu duvarların binanın davranışını önemli ölçüde etkilediğini göstermektedir. Bu çalışmada da elde edilen periyotlar, özellikle doğrusal hesapta dolgu duvarların da taş1yıc1 sistem elemanı olarak göz önünde bulundurulmaları gerektiğini göstermiştir.

\section{Kaynaklar}

[1] Furtado, A., Rodrigues, H., Arêde, A., Modelling of Masonry Infill Walls Participation in the Seismic Behaniour of RC Buildings Using OpenSees, Int. J. Adv. Struct. Eng., 7, (2015) 117-127.

[2] Rodrigues, H., Varum, H., Costa, A., Simplified Macro-Model for Infill Masonry Panels , J. Earthq. Eng., 14, (2010) 390-416.

[3] Smyrou, E., Blandon, C., Antoniou, S., Pinho, R., Crisafulli, F., Implementation and Verification of a Masonry Panel Model for Nonlinear Dynamic Analysis of Infilled RC Frames , Bull. Earthquake Eng., 9, (2011) 1519-1534.

[4] Cavaleri, L., Fossetti, M., Papia, M., Infilled Frames: Developments in the Evaluation of Cyclic Behaviour Under Lateral Loads, Structural Eng. And Mechanics, 21, (2005) 469-494.

[5] Zarnic, R., Tomazevic, M., An Experimentally Obtained Method for Evaluation of the Behaviour of Masonry Infilled RC Frames, Proceedings of the 9th World Conference on Earthquake Engineering, (1998), Kyoto.

[6] Fiorato, A.E., Sozen, M.A., Gamble, W.L., An Investigation of the Interaction of Reinforced Concrete Frames with Masonry Filler Walls, Report No. UILU-ENG 70-100, University of Illinoi, Urbana-Champaign, IL, (1970). 
[7] Hatzigeorgiou, G.D., Kanapitsas, G., Evaluation of Fundamental Period of Low-Rise and Mid-Rise Reinforced Concrete Buildings, Earthquake Eng. And Structural Dyn., 42, (2013) 1599-1616.

[8] TBDY 2018, Türkiye Bina Deprem Yönetmeliği, Çevre ve Şehircilik Bakanlığı, Ankara, Türkiye, (2018).

[9] SAP2000, Structural Analysis Program, Computer and Structures.

[10] TS 500-2000, Betonarme Yapıların Tasarım ve Yapım Kuralları, Türk Standartları Enstitüsü, Ankara (2000).

[11] Polyakov, S.V., On the Interaction between Masonry Filler Walls and Enclosing Frame when Loaded in the Plane of the Wall, Earthquake Eng. Research Institute, (s.36-42), (1960) San Francisco.

[12] Holmes H., Steel frames with brickwork and concrete infilling, Proceedings of the Institute of Civil Engineers, 19, (1961) 473- 478.

[13] Smith, B.S., Behaviour of the square infilled frames, Journal of Structural Div., ASCE, 92, (1966) 381-403.

[14] Smith, B.S. ve Carter, C., A method of analysis for infilled frames, Proc., Instn. Civ. Engrs., 44, (1969) 31-48.

[15] Mainstone, R.J., On the stiffnesses and strengths of infilled frames, Proc. Inst. Civ. Engrs., Supp. (4), (1961) 57-90.

[16] FEMA 306, Federal Emergency Management Agency, Evaluation of Earthquake Damaged Concrete and Masonry Wall Buildings: Basic Procedures Manual, FEMA-306, Washington, DC (1998).

[17] Ersin, U.D., Yuksel, E., Kocak, A., Hayashi, M. and Karadogan, F., System identification by means of micro tremor measurements, Second Japan-Turkey Workshop on Earthquake Engineering, Volume I, (s. 633 -648) (1998) Istanbul.

[18] TDY 1998, Türk Deprem Yönetmeliği, Bayındırlık ve İskan Baknalığı, Ankara (1998).

[19] UBC, Uniform Building Code, Structural Design Requirements, (1997).

[20] Goel, R.K. ve Chopra, A.K., Period formulas for momentresisting frame buildings, Journal of Structural Engineering, ASCE, 123(11), (1997) 1454-1461.

[21] Guler, H., Yuksel, E., Kocak, A., Estimation of the Fundamental Vibration Period of Existing RC Buildings in Turkey Utilizing Ambient Vibration Records, J. of Earthq. Eng., 12, (2008) 140-150.

[22] Koçak, A., Yildirim, M.Y., Effects of Infill Wall Ratio on the Period of Reinforced Concrete Framed Buildings, Advances in Structural Eng., 14, (2011) 731743.

[23] Koçak, A., Börekçi, M., ve Zengin, B., Period formula for RC frame buildings considering infill wall thickness and elasticity modulus, Scientia Iranica Transaction A, 25(1), (2018) 118-128. 